\title{
SIMPLEMENTE ENFERMERÍA
}

\author{
YolandA RIVADO
}

Empiezo a escribir esta historia sin saber si realmente mis palabras llegarán a algún sitio, si mi mensaje será oído, o mis sentimientos serán transmitidos. Sin saber si esto ayuda, o sirve de algo, si con esta simple narración se podrá cambiar algo.

Aún soy estudiante de enfermería, consciente de mi insignificancia en el maremagnum de instituciones y personal que forman parte del servicio nacional de salud. Pero, al fin y al cabo un engranaje más de la vida, para lo bueno y lo malo. Y para mí lo bueno fue comenzar a estudiar mi carrera.

Aunque parezca un tópico lo mio fue vocacional, sabía lo que quería y no paré hasta lograrlo. Pero tranquilos, no voy a hablar aquí sobre mi vida; no por otra cosa, si no porque nosotros, estudiantes o profesionales, a pesar de lo que piensen muchos, no somos los protagonistas de esta historia, el papel principal lo intrerpretan otros, los llamados pacientes, clientes, usuarios, y otros muchos nombres más para definir a las personas que acuden a nosotros porque su salud no es la que debería ser. Pero éste es otro tema del que se podría hablar largo y tendido.

Recuerdo que los primeros meses de clase estabamos todos desilusionados porque, según nosotros, las materias que nos impartían no tenían nada que ver con nuestra visión de la enfermería. Biología celular, bioestadística, bioquímica, fundamentos de enfermería,... Una larga lista hasta completar unas 16 asignaturas, con las que aumentamos nuestros conocimientos sobre el cuerpo humano y algo de relación con el paciente. ¿Y ya está? ¿eso era enfermería? Un mar de dudas nos azotaban.

El tiempo trancurrió y todos esperábamos impacientes las listas donde nos ponían el servicio dónde íbamos a ir durante las prácticas. Ese día llegó.

Todos nos agrupamos ante la vitrina, ansiosos por ver donde estaríamos los próximos cuatro meses de nuestra vida. Yo también me acerqué a mirar, el corazón se me salía y el sudor empapaba mi piel. O,P,Q,R...allí estaba: Rivado Ortega, Yolanda (osea yo). Primer y segundo módulo ,ONCOLOGÍA, después centro de salud de Santa Pola y más tarde urología. Pero apenas me di cuenta de los últimos servicios, la palabra ONCOLOGÍA me había embrujado.

De repente todos mis ánimos se fueron al suelo y fue como si sobre mi cayera un peso tal que me dejara sin fuerzas.

A los pocos sugundo comencé a darle vueltas a la cabeza. Oncología, esa palabra sonaba muy fuerte. Enseguida me imaginé una planta repleta de gente que se estaba muriendo, agonizante, triste, desolada, con llanto.

¿Qué podía hacer yo, pobre de mí, estudiante de primero? ¡Pero si ni siquiera sabía poner una vía! Es más ¡No sabía hacer nada! "Que pena que hasta el año que viene no estudiemos Cuidados Paliativos" -pensé-. De repente se apoderó de mí un miedo inmenso, recordé la muerte de mi padre tres años atrás y me planteé si podría hacer frente a la muerte otra vez. Fue entonces cuando recordé a las enfermeras de la U.C.I. dónde él había estado ingresado. Me ayudaron algunas, otras, no. En estos sitios es dónde más se puede hacer por las personas, me dije a mí misma para convencerme. Y así fui haciendome a la idea, o al menos intentandolo.

Fue curiosa la reacción de la gente. Cuando me preguntaban el servicio que me habían asignado y yo contestaba "onco" había como dos posturas definidas. La primera era poner cara de pena, decir un pequeño ¡oh!, para luego proseguir diciendo "Bueno también está bién", como dándome su aprobación. La segunda era de la gente que no sabía el significado de la palabra oncología. Entonces, con decir simplemente cáncer, se les desencajaba la caray me decían :"¿No puedes ir a otro sitio?" (Esta postura la encabezaba mi familia, a la que no le hacía ninguna gracia que me pasara tantas horas diarias entre gente que se estaba muriendo, según ellos).

Pero yo les rebatía con la misma argumentación que tiempo antes yo ya me había dado: allí es dónde más se puede hacer por las personas.

El invierno pasó y el nuevo año comenzó. El mes de enero pasó rápido y nos plantamos enseguida en el día de inicio de las prácticas. 
Estábamos todos de los nervios. Nos agrupábamos y no parábamos de hablar sobre cómo nos irían las cosas.

Después de la presentación y discurso de bienvenida (ahora ya conocidos), nos dividimos y nos dirigímos por grupos a nuestros respectivos servicios, guiados por un responsable de prácticas.

Por fín tocó el turno ala $4^{\mathrm{a}}$ derecha de la Maternal. Y allí nos plantamos, con nuestro uniforme y zuecos nuevos, una libreta y un boli. Nos presentaron a la supervisora y ésta a las enfermeras del turno de esa mañana.

Recuerdo aquel día como si fuera ayer. Todo era nuevo y desconocido. No me habría sentido más perdida si hubiera saltado en paracaídaas, en medio de una ciudad extranjera, sin nadie a mi alrededor que hablara mi idioma.

Cuando esa misma mañana nos fuimos a desayunar, mientras andábamos por los pasillos hacia la cafetería, me di cuenta, por primera vez, del poder que causa la bata blanca en las personas de tu alrededor y en ti misma. Los demás te miran diferente, con más respeto, reconociendo en ti a alguien importante, diferente, y a la vez, parte de un todo. La bata balanca es como una marca de ganadería que sólo unos pocos pueden llevar. Unos pocos con más conocimientos, $\mathrm{y}$, por lo tanto, con más poder sobre los demás.

De nuevo en la planta acompañé a una enfermera a realizar una cura. Entré en la habitación con ella, acompañadas de nuestro infatigable e indispensable carro de curas. En la habitación había un hombre tapado con una sábana, aparentemente normal. A su lado estaba su mujer. Llamémosles Antonio y María.

Antonio estaba sudoroso y algo pálido. Era un hobre alto y grueso. La enfermera entró con la soltura que te da la experiencia y el haber tratado mucho con tus pacientes, hasta rel punto de conocerlos al dedillo. Yo dije un timido "Hola" y me situé a un lado para observar. La enfermera retiró la sábana y dejó al descubierto el abdomen de Antonio. Apareció ante mis ojos una cicatriz que le atravesaba de arriba abajo. También tenía en su lado izquierdo una bolsa pegada a un estoma. La enfermera retiró cuidadosamente la bolsa para limpiar el estoma y cambiar la bolsa, mientras charlaba amistosamente con él sobre cómo se encontraba esa mañana.
No sé aún la causa, no soy de las que impresionan con la sangre o similares, pero empezó a embargarme una sensación muy extraña de, vertiginosa, con nauseas y sin fuerzas para sostenerme en pie. Tuve que salir e irme al baño para echarme agua a la cara. Levanté la cabeza y mirándome al espejo decidí en aquel preciso instante, si entraba en esa habitación para hacer mi trabajo y seguía con mi carrera o me iba para siempre de allí. Opté por lo primero y volví a entrar a la habitación. Esta vez busqué la historia de Antonio para conocerle un poco más, y ya dentro comencé a charlar un poco con él y su mujer.

Ese primer día tomé contacto no con los pacientes, sino con el hospital, su rutina, su personal. Si he de ser sincera, ese día me limité a observar, a ver lo que por sentido común me parecía correcto o menos correcto. No entré apenas a las habitaciones, supongo que por miedo e inseguridad; más tarde éstos sería lo primero en mis actividades.

El segundo día decidí comenzar a actuar como creía que debía ser una enfermera. Me leí las historias de mis pacientes, preguntando lo que no sabía, me apunté sus nombres, escuche las incidencias de la noche y las apunté, para acto seguido pasarme por todas las habitaciones con la intención de conocerles y darme a conocer.

Con cada persona que conocía se abría ante mis ojos un nuevo mundo, una nueva visión sobre la vida, una experiencia, una ilusión, una esperanza, una historia, una sonrisa, un llanto. Fue entonces cuando comencé a descubrir la verdadera enfermería, esa que ofrece una sonrisa, una mano, una actitud de escucha, un hombro dónde apoyarse...

Hubo una paciente, llamémosle Raquel, que hizo que me diera cuenta de muchas cosas.

Raquel tenía un tumor cerebral, la primera vez que le vi estaba postrada en su cama, semiincosciente. El tumor le presionaba algunas partes de su cerebro y esto le producía ciertos déficits en las capacidades físicas como moverse, orientarse, hablar, comer, etc. Pero lo que más me llamó la antención de Raquel fueron sus ojos. Unos ojos de color azul, brillantes, llenos de vida, que destacaban sobre su faz, tan pálida y frágil, en su cabeza, ahora sin cabello. Tenía creo recordar 38 años y su cara transmitía lucha, esperanza, firmeza, bondad. 
Su enfermedad hacía que dependiera mucho de los profesionales de enfermería, así que la interacción con ella fue muy grande. Raquel era sin duda, alguien especial en la planta, supongo que por el tiempo que llevaba ingresada en planta

Sus necesidades iban desde realizarle la higiene básica hasta, por ejemplo leerle un libro. Ya veis, algo tan elemental como eso es Enfermería. Raquel se sometía a una tratamiento con quimioterapia. Con el paso del tiempo fue mejorando. Pasó de un estado estuporoso a ser plenamente consciente de sus actos. De un habla casi ininteligible a poder transformar todos sus pensamientos a palabras con significado (aunque, eso sí, con su acento extranjero). Ese nuevo estado de Raquel trajo consigo un nuevo plano de interacción con ella. Ahora podías charlar sobre su ciudad natal, o sobre su casa, aquí en San Vicente. Le encantaba su casa, estaba deseando irse del hospital con ella para poder tomar el sol en su jardín. Soliamos salir por fuera del hospital con ella para darnos un paseo y que nos diera un poco el aire y el sol de la mañana. A veces nos cantaba pequeños trozos de las canciones de su tierra y nos explicaba su significado. Aun conservo una estampa que me regaló con la virgen de su tierra.

Pero, de entre todo lo que aprendí de ella, lo que más me llamó la atención fue su creencia firme de que se iba a poner bien. No tenía razones científicas ni pruebas de laboratorio, solo Fé, ella y sus ganas de vivir, tantas que se contagiaban. En planta todos creíamos que a ese ritmo no tardaría en regresar a su casa.

Ese día llegó, casi después de tres meses tras yo conocerla. La cara no le cabía en si de gozo. Todo era un revuelo con los preparativos de su ida. Nosotros nos alegramos mucho por ella. Tenía que seguir el tratamiento en casa, y volver de vez en cuando, pero ya no sería lo mismo: ahora iba a estar en su CASA. Nos besó a todos y se despidió agradeciendonos a todos la ayuda prestada.

Me fui a otros servicios, pero cada vez que pasaba por oncología preguntaba a los compañeros por ella. Le iba bien, eso era lo importante. Hasta que un día, que volví a preguntar por ella, me dijeron que había vuelto a ingresar, su estado había empeorado mucho. Pasé a verla y me encontré a la Raquel de la primera vez. Me acerqué a ella y dándole un beso me despedí de ella, consciente de que ya no la volvería a ver más. Fue triste pero me que- dó la satisfacción de haber compartido unos momentos inolvidables.

Sinceramente, no he conocido en mi vida personas como las que estaban ingresadas en oncología. Cada día se aprendía algo nuevo de ellas. ¡Qué equivocada estaba cuando pensaba que todo era tristeza y llanto, y que yo iba ayudarles a ellos, esgrimiendome salvadora del mundo!. Sorprendentemente eran ellos los que te animaban a ti, y bromeaban sobre cualquier cosa. Sabían lo que tenían y lo afrontaban, cada uno a su manera, unos días mejor que otros, pero ¿quién podía reprochárselo?

Cuando acabé mis prácticas me di cuenta que no solo había aprendido de los profesionales de la planta, sino que me había enriquecido como persona, había conocido otras vidas, otros valores, otras creencias. Quizás contrastaban con las mías, pero sin duda este hecho me ayudó a realizarme como persona, a comprender mejor a los demás, a ponerme en su lugar, a no juzgar, y sobre todo a ser más humana.

Porque si algo aprendí en esa planta es humanidad. El como con coger la mano de un paciente calmaba su miedo y su ansiedad, cuando le estaban realizando una punción lumbar, o como el dar un masaje en la espalda puede dar como resultado una magnífica sonrisa, o simplemente por escuchar a alguien te de mil gracias. Hablamos de enfermería humanística, pero esa designación debería ser una redundancia ¿Cómo se puede desunir la humanidad y la enfermería? ¿No forman un todo completo, que caminan de la mano? ¿Qué seríamos entonces? ¿Robots? ¿Personas con ciertos conocimientos de fisiopatología y anatomía?

No podemos obviar que somos personas, y que trabajamos también con personas. Personas con sentimientos, como nosotros, con ansiedades y miedos, con tristrezas y alegrías. ¿Acaso nosotros podemos separar nuestro lado humano de nuestro cuerpo físico? Imposible ¿Cómo separar entonces la enfermería del humanismo?

Tenemos la suerte de tener una profesión que está en continuo contacto con las personas ¡Aprovechémoslo! Que no sea una carga para nosotros. Veámoslo como un reto, tanto profesional como personal, que hay que superar día a día. Tarea dificil, pero no imposible. Entre todos podemos hacer, SIMPLEMENTE ENFERMERÍA. 